7. Reprod. Fert. (1972) 28, 427-431

\title{
EGG TRANSFER IN THE COW: SYNCHRONIZATION REQUIREMENTS
}

\author{
L. E. A. ROWSON, R. A. S. LAWSON, R. M. MOOR \\ AND A. A. BAKER * \\ University of Cambridge, Unit of Reproductive Physiology and Biochemistry, \\ 307 Huntingdon Road, Cambridge
}

(Received 14th May 1971, accepted 22nd fuly 1971)

Summary. Eggs were transferred surgically from fifty-three donor heifers to ninety-nine recipients which were allocated to different groups according to the degree of synchronization of oestrus between donor and recipient.

The pregnancy rate obtained was $0 \%, 30 \%, 52.2 \%, 91 \cdot 1 \%, 56.5 \%$, $40 \%$ and $20 \%$ where the degree of synchronization of the recipient in relation to the donor was $-3,-2,-1,0,+1,+2,+3$ days, respectively. Storage of eggs for periods of up to $6 \mathrm{hr}$ did not influence the pregnancy rate.

The high pregnancy rate obtained where synchronization was exact may have been due to the rejection of retarded or abnormal eggs before transfer.

It is concluded that the synchronization requirements for successful egg transfer in the cow are slightly more acute than in the sheep and should not vary by more than \pm 1 day.

\section{INTRODUCTION}

It is known that in order to obtain satisfactory pregnancy rates on egg transfer relatively close synchronization of oestrus is a necessity in a number of species; rabbit (Chang, 1950), rat (Noyes \& Dickmann, 1960), mouse (McLaren \& Michie, 1956; Doyle, Gates \& Noyes, 1963), sheep (Moore \& Shelton, 1964; Rowson \& Moor, 1966) and pig (Webel, Peters \& Anderson, 1970).

No such data are available for the cow and the experiments described here were designed to investigate such requirements.

\section{MATERIAL AND METHODS}

A total of 152 maiden heifers was used in these experiments. All heifers, both donors and recipients, were run with a vasectomized bull whose brisket was coated with coloured grease. They were examined several times daily for service marks indicating oestrus.

* Present address: Queensland University, Veterinary School, St. Lucia, Queensland. 


\section{Donors}

Superovulation was induced in the fifty-three donors by an injection of 1500 to 2500 i.u. PMSG on Day 16. They were inseminated either once or twice during oestrus, using semen obtained from the Cambridge AI Centre.

Eggs were recovered from the donors on Days 3 to 7 after the onset of oestrus, using either the technique of Rowson, Moor \& Lawson (1969) or that of Hunter, Adams \& Rowson (1955).

After recovery from the donor animals, the eggs were held in covered dishes in sterile TCM 199 at $37^{\circ} \mathrm{C}$ until the time of transfer to the recipients. The maximum period of storage from recovery to transfer was $365 \mathrm{~min}$. Eggs showing any abnormality or which were retarded in development were discarded. Where donors provided eggs for a number of recipients, these were, as far as possible, distributed among the various synchronization groups, but, because of the limited number of recipients available at any one time, this was not always possible.

TABLE 1

PREGNANCY RATES OBTAINED FOLLOWING SYNGHRONOUS AND ASYNGHRONOUS EGG TRANSFER TO RECIPIENT COWS

\begin{tabular}{c|c|c|c}
\hline $\begin{array}{c}\text { Variation from exact } \\
\text { synchronization } \\
\text { (days) }\end{array}$ & $\begin{array}{c}\text { No. of } \\
\text { animals }\end{array}$ & $\begin{array}{c}\text { No. } \\
\text { pregnant }\end{array}$ & $\begin{array}{c}\text { Pregnant } \\
(\%)\end{array}$ \\
\hline 0 & 23 & 21 & $91 \cdot 1$ \\
-1 & 23 & 12 & $52 \cdot 2$ \\
+1 & 23 & 13 & $56 \cdot 5$ \\
-2 & 10 & 3 & $30 \cdot 0$ \\
+2 & 10 & 4 & $40 \cdot 0$ \\
-3 & 5 & 0 & 0 \\
+3 & 5 & 1 & $20 \cdot 0$ \\
\hline
\end{tabular}

\section{Recipients}

Ninety-nine maiden Friesian $\times$ Hereford or Jersey heifers were used as recipients. Twenty-three recipients received eggs from donors where synchronization was exact (Day 0) and an equal number in each of the groups where the recipients were in oestrus 1 day earlier $(+1)$ or 1 day later $(-1)$ than the donors. Ten animals per group received eggs where synchronization was \pm 2 days and five animals per group where it was \pm 3 days (Table 1 ).

As eggs do not normally enter the uterus of the cow before Days 3 to 4 after the onset of oestrus, no transfers were made to recipients before Day 3. Thus, where recipients were in oestrus 3 days later than the donors, eggs were recovered from the donors on Day 6 so that they could be transferred to the uteri of Day-3 recipients. After recovery, the recipients were run with a raddled, vasectomized bull. Animals which had not returned to oestrus after 42 days were examined by rectal palpation to confirm pregnancy. They were then either slaughtered at 2 or 3 months or allowed to go to term. The tracts of slaughtered animals were checked at autopsy to confirm that they were pregnant. 


\section{RESULTS}

The pregnancy rate obtained in the various synchronization groups are shown in Table 1.

When exact synchronization between the oestrous cycles of donor and recipient was preserved, an extremely high pregnancy rate was obtained. The proportion of recipients becoming pregnant fell sharply when the time of onset of oestrus of donor and recipient varied by 1 or 2 days and where there was a difference of 3 days, only a single pregnancy was obtained in ten recipients. A comparison between the results obtained for the cow in these experiments with those for the sheep obtained by Rowson \& Moor (1966) is illustrated in Text-fig. 1 .

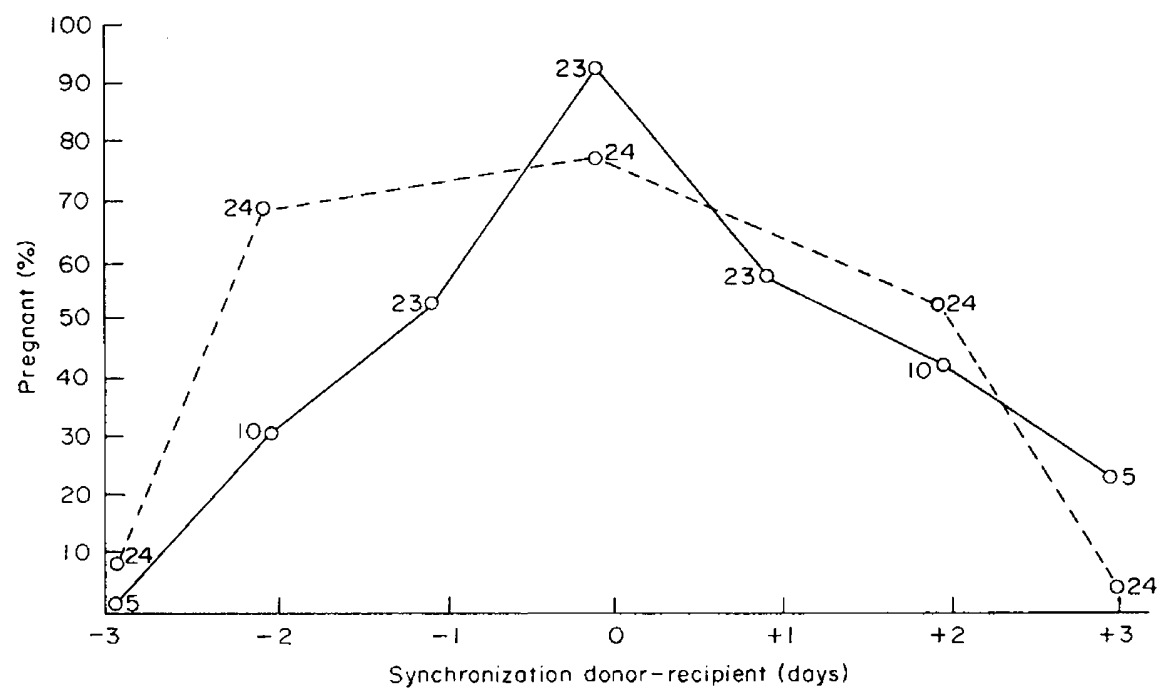

TExT-FIG. 1. The effect of the degree of synchronization of donor and recipient on pregnancy rate: - $\longrightarrow$ cattle in present experiment; - - - - , sheep (Rowson \& Moor, 1966). The number of animals is given against each symbol.

Where several recipients received eggs from a single donor, there was none in which the most asynchronous transfer succeeded and the more closely synchronized transfer failed. In fact, the transfer of all the eggs from a single donor failed only in one group of four recipients. The donor had provided thirteen eggs, twelve of which were fertilized. Four eggs were transferred singly to animals in Groups $+1,-1,-1,+2$ and the remaining eggs were transferred to the oviduct of a rabbit. Despite the failure of all four cow recipients to become pregnant, the eggs transferred to the rabbit all developed normally over the 3 days following transfer and it is, therefore, unlikely that pregnancy failure in these recipients was due to defective eggs. The evidence would suggest, therefore, that the results were not influenced to any degree by failure always to randomize the eggs obtained from one donor over all groups. The number of eggs (one or two) transferred to the recipient had no influence on the pregnancy rate, nor was the rate significantly affected by the period of storage of eggs before transfer. In fact, the small number of transfers carried out after a storage 
period of $>200 \mathrm{~min}$ was associated with a higher pregnancy rate (Table 2). The average interval between the pre- and post-transfer oestrus was $22 \cdot 2$ days for the ' -1 day' group, 26.6 days for the ' +1 day' group (this included two double cycles of 36 days), $24 \cdot 2$ for the ' -2 day' group (including one double cycle of 41 days) and 19.2 for the ' +2 group'. In all groups, if the double cycles are omitted, the average length is normal.

TABLE 2

EFFECT OF EGG STORAGE ON PREGNANCY RATE IN COWS WITH DIFFERING SYNGHRONIZATION TIMES

\begin{tabular}{|c|c|c|c|c|c|c|c|c|}
\hline \multirow{3}{*}{$\begin{array}{c}\text { Variation from exact } \\
\text { synchronization } \\
\text { (days) }\end{array}$} & \multicolumn{8}{|c|}{ Interval between egg recovery and transfer (min) } \\
\hline & \multicolumn{2}{|c|}{$<100$} & \multicolumn{2}{|c|}{100 to 200} & \multicolumn{2}{|c|}{200 to 300} & \multicolumn{2}{|c|}{$>300$} \\
\hline & $\begin{array}{l}\text { No. of } \\
\text { animals }\end{array}$ & $\underset{\text { pregnant }}{\text { No. }}$ & $\begin{array}{c}\text { No. of } \\
\text { animals }\end{array}$ & $\underset{\text { pregnant }}{\text { No. }}$ & $\begin{array}{l}\text { No. of } \\
\text { animals }\end{array}$ & $\underset{\text { pregnant }}{\text { No. }}$ & $\begin{array}{l}\text { No. of } \\
\text { animals }\end{array}$ & $\underset{\text { pregnant }}{\text { No. }}$ \\
\hline $\begin{array}{r}0 \\
-1 \\
+1 \\
-2 \\
+2\end{array}$ & $\begin{array}{r}13 \\
8 \\
12 \\
1 \\
6\end{array}$ & $\begin{array}{r}12 \\
6 \\
5 \\
1 \\
0\end{array}$ & $\begin{array}{r}10 \\
14 \\
6 \\
6 \\
2\end{array}$ & $\begin{array}{l}9 \\
6 \\
3 \\
2 \\
2\end{array}$ & $\begin{array}{l}1 \\
3 \\
1 \\
1\end{array}$ & $\begin{array}{l}0 \\
3 \\
0 \\
1\end{array}$ & $\begin{array}{l}2 \\
2 \\
1\end{array}$ & $\begin{array}{l}2 \\
0 \\
1\end{array}$ \\
\hline Totals & 40 & 24 & 38 & 22 & 6 & 4 & 5 & 3 \\
\hline Pregnant $(\%)$ & \multicolumn{2}{|c|}{$60 \cdot 0$} & \multicolumn{2}{|c|}{$57 \cdot 9$} & \multicolumn{2}{|c|}{$66 \cdot 7$} & \multicolumn{2}{|c|}{$60 \cdot 0$} \\
\hline
\end{tabular}

\section{DISGUSSION}

The results obtained in these experiments indicate that the necessity for synchronization of the oestrous cycle is more acute in the cow than in the sheep, where it was shown by Rowson \& Moor (1966) that variation from exact synchronization of \pm 2 days could be well tolerated (Text-fig. 1). The present work indicates that, even with a variation of \pm 1 day, there was an appreciable fall in the percentage of animals which became pregnant. A striking feature of these experiments is the extremely high percentage of pregnancies obtained where synchronization was exact $(91 \cdot 1)$, a figure far above that which is considered normal following a single insemination. A possible explanation of this may be that all eggs which showed any abnormality were discarded before transfer. It could be argued from this that a high proportion of normal embryonic loss must be due to abnormalities occurring during the very early stages of development and that the high pregnancy rate in these experiments resulted from selection of the normally developing embryos. Under the conditions of these experiments, fertilization failure was uncommon where small numbers of ovulations were induced.

The results also serve to illustrate that there must be rapidly changing requirements within the uterus for embryonic survival and it is not hard to visualize that under certain conditions of management and feeding, a state of asynchrony may develop between embryo and uterus which could result in an appreciable fall in conception rate. Because of the more acute synchronization requirements of the cow, such a change would be reflected more sharply than 
in the sheep. It is possible that this is a factor to be considered in herds showing temporary infertility which is responsible for most of the economic loss in this field. It is, therefore, of importance to establish exactly the nature and timing of the physiological relationships between the developing embryo and uterus in normal animals. It may then be possible to introduce conditions known to produce infertility and to study their effect on the endometrial secretions.

\section{ACKNOWLEDGMENT}

The authors wish to express their thanks to Professor T. R. R. Mann for reading through the manuscript and for his encouragement during these experiments.

\section{REFERENCES}

Chang, M. C. (1950) Development and fate of transferred rabbit ova or blastocyst in relation to the ovulation time of recipients. 7. exp. Zool. 114, 197.

Doyle, L. L., Gates, A. H. \& Noyes, R. W. (1963) Asynchronous transfer of mouse ova. Fert. Steril. 14, 215.

Hunter, G. L., Adams, C. E. \& Rowson, L. E. (1955) Inter-breed ovum transfer in sheep. J. agric. Sci., Camb. 46, 143.

McLaren, A. \& Mrchie, D. (1956) Studies on the transfer of fertilized mouse eggs to uterine fostermothers. 1. Factors affecting the implantation and survival of native and transferred eggs. 7. exp. Biol. 33, 394.

Moore, N. W. \& Shelton, J. N. (1964) Egg transfer in sheep. Effect of degree of synchronization between donor and recipient, age of egg, and site of transfer on the survival of transferred eggs. 7. Reprod. Fert. 7, 145.

Noyes, R. W. \& Dickmann, Z. (1960) Relationship of ovular age to endometrial development. F. Reprod. Fert. 1, 186.

Rowson, L. E. A. \& MooR, R. M. (1966) Embryo transfer in the sheep: the significance of synchronizing oestrus in the donor and recipient animal. F. Reprod. Fert. 11, 207.

Rowson, L. E. A., Moor, R. M. \& LAwson, R. A. S. (1969) Twinning in cattle. Vet. Rec. 88, 583.

Webel, S. A., Peters, J. B. \& Anderson, L. L. (1970) Synchronous and asynchronous transfer of embryos in the pig. F. Anim. Sci. 30, 565. 